\title{
The Reading Anxiety Survey of Science and Engineering Majors' in Higher Vocational College
}

\author{
Ying Liu \\ Department of Information Engineering, Shandong Vocational College of Light Industry, Zibo \\ Shandong 255300, China
}

81713055@qq.com

Keywords: Reading anxiety, Science and Engineering Majors, Higher Vocational College.

\begin{abstract}
The author picked up 176 Science and Engineering majors from Shandong Vocational College of Light Industry as subjects and used Foreign Language Reading Anxiety Scale, Shan Dong Practical English Test for College and computer software SPSS as instruments. And the data were conducted in process of descriptive statistics and correlation analysis. The results demonstrated: 1. Science and Engineering majors' do experience high English reading anxiety. 2. English reading anxiety has been influencing students' reading scores. It is hoped that the results of investigation would provide realistic and theoretical cogent evidence for English teaching so that teachers can adopt measures to regulate students' reading anxiety.
\end{abstract}

\section{Introduction}

Affective factors play a significant role in language learning, for example Foreign Language Anxiety. During English teaching process, I found that the number of students in vocational college who suffered from anxiety were far higher than those from that of other subjects. Not having good English foundations, they feel completely in the dark about how to learn English well and suffer much more anxiety. Their Foreign learning anxiety (FLA) has greatly influenced their learning achievement, especially in reading. Unfamiliar with words and structures in reading materials, students feel psychological disorder in reading, which tends to cause distraction and then make reading incoherent and finally affect the whole understanding of discourse. Studying like this in long run leads to high reading tension and anxiety. Meanwhile, the atmosphere in English reading class is dull and most of the students are unwilling to join in class activities due to the obsolete teaching method which has further aggravated the students' reading anxiety. The teacher tends to teach reading by translating words and sentences of the context and few chances are given to students to think and speak.

A great many experiments have been conducted to prove that Non-English majors really suffer high degree of foreign language reading anxiety (FLRA) and students' English achievement and their reading anxiety are negatively correlated. In other words, FLRA has negative effect on English learning of non-English majors and the higher anxiety level they suffer, the worse reading achievement they got. Thus, effective teaching methods are required to create low anxiety classroom environment so that students can study with relaxed and positive attitude. As a result, students' reading anxiety will be alleviated and their learning achievement will be improved.

The author selected 176 Science and Engineering majors in Shandong Vocational College of Light Industry to carry out a reading anxiety investigation. The investigation used Foreign Language Reading Anxiety Scale and reading test as instruments. Then computer software SPSS was adopted to analyze the data collected from the questionnaires and tests. It is hoped that the results of investigation would provide realistic and theoretical cogent evidence for English teaching so that teachers can adopt measures to regulate students' reading anxiety.

\section{Literature Review}

The research on Foreign Language Anxiety (FLA) started in the field of the educational psychology in the 1940s. From the 1990s, researchers began to focus on the specific aspects of language anxiety. 
The researchers have a found that foreign language learning anxiety in listening, speaking, reading and writing skills behave differently.

In 1999, a preliminary study of reading anxiety was carried out in 30 intact first-semester classes of Spanish, Russian and Japanese by Saito and Garza. Saito et al. (1999) proved that foreign language anxiety is a unique type of anxiety which is different from general foreign language anxiety. Reading anxiety can be thought as a type of specific phobia or an anxiety producing reaction towards reading. Sellers (2000) conducted a study on relationship between anxiety and reading. He chose 89 students from a university, whose foreign language is Spanish. He used Foreign Language Classroom Anxiety Scale and FLRAS adapted from Zbornick and Wallbrown (1991) to examine subjects' anxiety levels. Besides, Cognitive Interference Questionnaire was also distributed to measure the number of "off task thoughts" of the subjects. The results finally showed that "foreign language reading anxiety is unique and distinguishable from general foreign language anxiety; learners with higher levels of foreign language anxiety also tend to have higher levels of foreign language reading anxiety and vice versa; moreover, learners with higher levels of anxiety have the tendency to experience more "off task thoughts" and recollect fewer important and less systematic language points than learners with lower levels of anxiety" (Sellers, 2000). Similarly, Putman (2010) showed that anxiety may lead to factors involved in one's orientation towards reading such as self-efficacy and motivation. For example, motivation and time spent reading is positively correlated (Pavonetti, Brimmer, \& Cipielewski, 2002), which then influences one's comprehension of passage (Guthrie et al., 1999). This is to say, a student suffering from reading anxiety will be unwilling to spend time reading because of anxiousness produced in reading, which will subsequently influence their reading comprehension in negative fashion. Reading anxiety must be considered in the presence of low-proficient reading achievement scores.

In China, anxiety studies mainly focus on general English anxiety, the researches about FLRA start relatively late, but the progress is rapid. Hao and He (2001) found reading anxiety will prevent students from correct understanding of the reading material. Zhang's (2002) used Satio's FLRAS to carry out study on reading anxiety. According to her finding, compared with Japanese and Korean students, European and American students experience lower anxiety when reading Chinese and feel more satisfied with their reading performance. Wang (2003) adopted FLCAS to conduct a study but only pointing out the difference among reading anxiety and other anxieties. Shi (2004) conducted a study of reading anxiety using non-English majors as the research subjects by employing FLRAS and CET-4 reading tests as the instruments and found that there existed reading anxiety in some college non-English majors in China. And Reading anxiety negatively impacted students' reading performance. What is more, they conducted a comparison between male students and female revealing that male students were more anxious than female students and female students got higher scores than male students. Chen (2005) found that students in higher vocational college generally have higher anxiety in English reading. Reading anxiety is negatively correlated with English achievement and has the significant forecast on English learning. The studies of Liao (2007) showed: non-English majors experience various degrees of English reading anxiety which has negative correlation with English reading achievement, and the students with various reading degree anxiety have significant difference in English achievement. Gan (2008) found that reading anxiety of Non-English Majors exists in common and anxiety and CET4 achievement was negatively related to each other. He (2008), employing 144 non-English majors in vocational colleges as the research subjects, made a survey and found that: the higher reading anxiety is, the worse the performance is. Wu (2012) did teaching experiment on characteristic of Non-English majors in higher vocational college, and proved: the correlation between English reading anxiety and reading achievement is significantly negative and the higher reading anxiety is, the lower the achievement is.

From the numerous studies conducted abroad and at home, we can conclude that correlation between FLRA and reading achievement is moderate and that the higher reading anxiety is, the lower the achievement is. 


\section{Methodology and Data Analysis}

\subsection{Research Questions and Subjects}

The author selected 176 Science and Engineering majors in Shandong Vocational College of Light Industry as the subjects of the study. Three questions would be solved in this study:

1. Do Science and Engineering majors in vocational college suffer English reading anxiety?

2. How does English reading anxiety influence English reading?

\subsection{Research Instruments and the Process of the Experiment}

In this study, three instruments were adopted-questionnaire and reading test. At first, students' English reading anxiety level was examined by questionnaire FLRAS designed by Satio \& Horwtiz (1999). The final score of FLRAS scale ranges from 20 to 100 in theory. The higher the scores are, the more reading anxiety students suffer. Those who score between 74 and 100 are high anxiety. Those who score between 63 and 73 have only moderate reading anxiety. Those who score between 20 and 62 indicated lower anxiety. Then, the reading comprehension part of Public English Test in June 2018 is distributed to 176 students. The results collected from the test and questionnaires would be used to find out the relationship between reading anxiety and reading achievement.

\subsection{Data Analysis}

\subsubsection{Analysis of level of English reading anxiety}

Table 1 Numbers and percentage of subjects at different anxiety level.

\begin{tabular}{|c|c|c|}
\hline Anxiety Level & N & P \\
\hline Low-anxiety (score 20-62) & 28 & $15.9 \%$ \\
\hline Moderate-anxiety (score 63-73) & 54 & $30.7 \%$ \\
\hline High-anxiety (score 74-100) & 94 & $53.4 \%$ \\
\hline
\end{tabular}

Note: (N: Numbers of subjects at different anxiety level; P: Percentage of subjects at different anxiety level.)

Table 2 Descriptive Statistics of FLRAS

\begin{tabular}{|c|c|c|c|c|}
\hline $\mathrm{N}$ & Mean & $\begin{array}{c}\text { Std. } \\
\text { Deviation }\end{array}$ & $\min$ & $\max$ \\
\hline 176 & 71.4222 & 10.8412 & 48.00 & 87.00 \\
\hline
\end{tabular}

The data from table 1 shows that the number of students obtained high reading anxiety level is as high as 94 . The percentage of high anxiety level is $53.4 \%$. In the table 2 , the minimum score is 48.000. The maximum score is 87.000. The mean score of experimental class is 71.4222 . The standard deviation of experimental is 10.8412 . The data indicate clearly that computer majors did experience serious reading anxiety.

3.3.2 Correlation Analysis Between English Reading Anxiety and Reading Achievement

Table 3 Correlation Analysis Between English Reading Anxiety and Reading Achievement

\begin{tabular}{|c|c|}
\hline Reading Anxiety Level & Test score \\
\hline Pearson's Correlation Coefficient & $-.283(*)$ \\
\hline Sig.(2-tailed) & .037 \\
\hline $\mathrm{N}$ & 176 \\
\hline \multicolumn{2}{c|}{$*$ Correlation is significant at the 0.05 level (2-tailed) }
\end{tabular}


Table 4 Different Levels of Reading Anxiety and Pearson's Correlation Coefficient

\begin{tabular}{|c|c|}
\hline Reading Anxiety Level & Test score \\
\hline Low-anxiety (score 20-62) & .022 \\
\hline Moderate-anxiety (score 63-73) & $-.245\left(^{* *}\right)$ \\
\hline High-anxiety (score 74-100) & $-.279\left(^{* *}\right)$ \\
\hline
\end{tabular}

**: Correlation is significant at the 0.01 level (2-tailed).

From table 3, Pearson's correlation coefficient is .283 and Sig.(2-tailed) is .037, which show that English learning anxiety influences students' reading scores significantly. Table 4 shows that the correlation between low anxiety and reading achievement was weak positive, and was not significantly. Correlation between moderate anxiety and high anxiety and reading achievement was negative correlation and was significant. That is to say, the higher reading anxiety the students suffer, the worse score the students get.

\section{Conclusion and Implications}

For the questionnaire, it is easy to find out computer majors' do experience high English reading anxiety. For the scores and questionnaire, we get the implication that English learning anxiety influences students' reading scores significantly. Correlation between moderate anxiety and high anxiety and reading achievement was negative correlation and was significant.

Based on the findings in this study, the state of reading anxiety of computer majors is very serious. And the teacher should face this problem squarely rather than skirt round them. And the level of reading anxiety should be examined and the sources of anxiety should be analyzed. Several notes should be paid more attention in reading teaching:

Firstly, the teacher should take measures to reduce the reading anxiety of students actively. In traditional reading teaching, students are given one or two passages and a number of questions about passages. After that, the teacher usually translates the passage word-by-word, sentence-by-sentence. It is very easy for teacher to become the learning center instead of students. Absolute power of teachers in the classroom can easily lead to the students' high anxiety. This out-of-date notion of English teaching learning should be abandoned.

Secondly, teachers can emphasize the importance of culture to language in English teaching, and also can deliberate infiltrate western culture into not only reading but also other English learning aspects by combining introduction of culture to explanation of language points or analyzing of western thinking style and so on. In short, students should realize the importance of culture by appropriate teaching methods of English teaching.

Thirdly, it is important to develop the reading strategies of students. The teacher should cultivate students the habit to use of different reading strategies. More word-attack and inference strategies training should be given to high reading anxiety learners, for instance, using background knowledge to guess word meaning and finding implied meaning of passage should be encouraged to use for the high anxious students in English reading. Especially, the structure analysis should be paid sufficient attention because this strategy is used the least among the six categories of reading strategies by both high-anxiety group and low-anxiety group. The ultimate aim is to improve reading proficiency and achievement, for reading strategies directly influence performance in reading.

\section{References}

[1] Aronson, E., Blanes N., SLephan, C, Sikes J, and Snapp M. The Jigsaw Classroom[M]-Beverly Hills, CA; Sage Publications Inc, 1978.

[2] Aronson, E., Bridgeman, D.\&Geffier, R. Interdependent interactions and proposal behavior[M]. Journal of Research and Development in Education.1978:12, 16-27.

[3] Aronson, E.\&Patnoe, S. The jigsaw classroom: building cooperation in the Classroom[M]. New York: Addison Wesley Longman, 1997. 
[4] Arnold, J. Affect in Language Learning[M]. Bengjing: Foreign Language Teaching and Research Press,2002.

[5] Barnett M A. More Than Meets the Eye: Foreign Language Reading[M]. New Jersey: Prentice-Hall Regents, 1989.

[6] Bailey, K. M. Competitiveness and Anxiety in Adult Second Language Learning: Looking at and Through the Diary Studies[M]. Rowley, MA: Newbury House, 1983.

[7] Bailey, P. et al. Foreign language anxiety and learning style[J]. Foreign Language Annals, 1999(32):63-76.

[8] Carrotll, D. W. Use of tire jigsaw technique in laboratory and discussion classes. Teaching of Psychology,1986 (13):208-210.

[9] Clarke, J. Piece of the puzzle: The jigsaw method. In S. Sharan (Ed) Handbook of cooperative learning methods. West CT: Greenwood Press, 1994. 